\title{
Research on the Influencing Factors and Countermeasures of the Development of Archives Information Resources
}

\author{
Na Yu \\ Yunnan JiaoTong College, Kunming, Yunnan, 650500
}

Keywords: Archives Information Resources, Influencing Factors, Countermeasure

\begin{abstract}
In this society, information resources have become the most important social resource. Therefore, how to develop and utilize information resources has become an important issue in our society. However, in today's era, many factors affect the development of information resources, resulting in the inability to fully utilize archival information resources. In this paper, the paper studies the influencing factors and countermeasures of archival information resource development.
\end{abstract}

\section{Introduction}

In the current era of multimedia, the role of information has gradually emerged. For enterprises, schools and other social institutions, information is wealth. With the gradual strengthening of archival information resource development and management technology, the use rate of information resources has gradually increased, but there are still many factors affecting the development of archive information resources in the development of specific archive information resources. These factors include low emphasis on archives, inadequate archival facilities, etc. These issues require effort to resolve, so that the role of archival information can be fully realized. This paper analyzes the influencing factors of archival information development and effective solutions to provide reference for the development and management of archive information.

\section{Current Factors Affecting the Development of Archival Information Resources}

In order to properly develop and manage archival information resources, it is necessary to know the factors that affect the development of archival information resources. It is necessary to analyze all these factors in an all-round way, and to analyze the solutions to these factors, so that the archive resources information the role is greatly reflected. The following are the factors that affect the development of archival information resources.

The importance of file management is self-evident, but today many staff in the file management department have not paid much attention to file management. At present, many archival resources with excellent utilization are affiliated with relevant government departments. These government departments often carry out file management according to the established management system. This management system is relatively traditional and has a relatively small number of management methods. This has led to many problems in the actual file information management work, which has seriously affected the use of file information. In addition, many current government leaders have not achieved a high level of awareness of the management of archival information, which has led to the low ability of the recruited file managers to work, making it difficult to make substantial progress in the development and utilization of archival resources information. . Therefore, the relevant archives management departments in China should recognize the importance of file management and gradually pay attention to information management and development.

Good file management facilities are an important basis for ensuring the quality of file management. However, due to the fact that many file management departments do not have enough knowledge about the development and use of archive information, this directly leads to insufficient funds for file management, lack of sufficient funds to ensure the purchase and application of file management facilities, and now the relevant file management departments Insufficient infrastructure has affected the development and utilization of archival information [1]. In addition, 
many related file management departments have purchased file management equipment, but these devices have not been updated with the times. File information management is a rather complicated task and requires the most advanced management equipment to support. The file management equipment is not updated in time, and the file information management work will fall into a lagging situation. Therefore, the relevant file management department should implement the purchase and upgrade of file management equipment.

File management is a work that requires advanced management models. However, many file management departments are not aware of this. The file management methods they adopt are more traditional management methods. In the specific management process, many management departments often use the physical file management mode to manage. Although this management mode has certain desirability, this management mode has serious problems of low efficiency, which seriously affects the file information. There are many reasons for this kind of factors. The biggest problem is that the management of archives information in China started late, and the management, development and utilization technologies have a serious lag compared with some developed countries in the world. So far, many file management departments still do not have a sound file management system to manage file resources. Therefore, the relevant file management departments should devote their energies to upgrading and developing the file management model that meets the development needs of the times.

File management personnel are the main implementers of the development and management of archive information resources. Therefore, file management personnel should have strong file management quality. However, the file management personnel of many file management agencies are currently unable to meet the needs of file management work. Although these file managers have certain file resource information management capabilities, their file information resource management methods can only meet some simple file information management tasks [3]. Some in-depth file management efforts are not within their management capabilities. In addition, the lack of a sound training mechanism in many relevant file management departments is also an important reason for the current lag in file management. Therefore, the archives management department of China should invest its energy into the quality improvement work of archives information resource management personnel, and thus greatly enhance the work quality of file management personnel, and finally greatly increase the use rate of archive resource information.

\section{Analysis of Effective Countermeasures for the Development of Archives Information Resources}

At present, relevant archives information resource management departments should recognize some problems existing in the current archive information resource management work, and analyze all these problems in an all-round way. It is necessary to find an effective countermeasure to meet the current archival resource development through analysis. Let the role of archival information resources be greatly enhanced. The following are effective countermeasures for the development of archival information resources.

At present, China's relevant archives and information management departments should establish the ideological concept of advancing with the times, and gradually pay attention to the management of archives information. In the specific work process, the archives information management department should establish a sound archive information resource management system as soon as possible, and then effectively develop the archive information resources [4]. In addition, the relevant archives information resource management departments should also rectify and develop the existing file management system, and abolish those lags that are difficult to keep up with the pace of the times, and then follow the development of the times to establish a new era that meets the needs of the times. The file management system, in order to effectively implement the new management system, China's relevant information management departments must adopt various supervision and incentive systems to urge managers to actively implement the file information resource management and development model in accordance with the new regulations, and then make the files Information resources are fully utilized. 
The archives information resource management and development work needs to be implemented, and the relevant archives information resource management departments in China should recognize the importance of equipment construction work [5]. In the specific equipment construction work, the relevant departments should increase the proportion of capital investment, and purchase some electronic equipment that meets the needs of modernization to manage the archives information resources. Relevant personnel should use modern electronic equipment to establish a standard archive database and archives. The purpose of database establishment is to greatly improve the development efficiency of archival information resources, so that file managers can efficiently search for archives and materials, thereby saving materials and manpower. In addition, relevant file management departments should also pay attention to the upgrading of archive information management equipment, and upgrade equipment in time to ensure the implementation of archive information management. To upgrade equipment work, it is necessary to fully study the file management equipment on the market that fits the unit. The upgraded device should be compatible with its own file information resource management work.

Today's file managers need to know that their traditional thinking mode has been difficult to adapt to the current archive information management. Therefore, the development and utilization of archival information resources requires relevant practitioners to change their traditional thinking mode. In the specific archive information resource management work and daily life, practitioners must actively accept the baptism of new concepts of file management. The study has greatly enhanced the knowledge of its own, and thus responded to the needs of information management of archive resources. Relevant file management departments should also pay attention to cultivating the professional ability of management personnel and new concepts. In the specific training process, it is necessary to establish long-term cooperative relations with some specialized training units, and let professionals be trained in the form of talent training. The quality has been greatly strengthened, and thus meets the needs of the archives management of the archives information management department.

In order to change the problem of the lag of management methods of many file management departments today, China's relevant archives management departments should invest their energy into the development and research work of new management models [6]. In the specific upgrade work, the relevant file management department should carry out the management mode upgrade work according to the actual needs of the file management department and the needs of the information users. First of all, the file management department should apply the network technology to the file information management work. Compared with the traditional file management mode, the network technology management mode has extremely high efficiency, which can greatly improve the efficiency of file management. And then establish a modern file information management model. The network technology management model also has strong sharing. At present, relevant information management departments in China can use network technology to upload existing resource files to the network platform to achieve resource sharing. Secondly, the modern resource management mode of the network model can also establish contact with other archives information resource management departments. Through the mode of communication and cooperation, each file management department can know the shortcomings of its own file information management, and then carry out targeted Insufficient, and ultimately the quality of file resource management has been greatly enhanced.

The work level of the archives information resource management team directly determines the quality of file management. Therefore, China's archives resource management department should invest energy into the work of strengthening the work level of the archives resource management team. In the specific work process, the archives management department must first invest funds into the establishment of the training system. The archives management department should regularly arrange the file management personnel to carry out training work, and their management level is greatly enhanced through training. The training content can be modern file management information technology learning, file management concept learning in the new era and so on. Secondly, the archives management department should invest energy in the recruitment of archives 
information posts, and upgrade the capacity of the archives information management team through recruitment, and ultimately improve the quality of archive management. Finally, the archives management department can formulate a series of systems to transform the knowledge structure of today's file management staff, expand the knowledge of staff, and enable their work ability to meet the needs of current archive information resource management work.

In addition to the above-mentioned essential work, the current file management department should strengthen the quality of the file information resource management work. The archives management department should also devote its energies to the development and publicity of archival information resources, so that the emphasis on the archives information resources in all walks of life in our country will be gradually strengthened, which will prompt the archives management departments to pay more attention to the management of archives information resources. Upgrade [7]. In the specific work of promoting archival information resources, the archives management department should cooperate with the propaganda media to let the community know the importance of the archives through the form of advertisements. In addition, the archives management department can also arrange for staff to go to various social organizations for direct publicity. In this way, the various agencies in the society gradually realize the importance of the archives, so that the role of archives resources can be fully exerted, and finally the archives management the department attaches importance to the upgrading of archive information management.

\section{Conclusion}

In summary, with the development of the times, today's society has gradually increased its emphasis on information. As the main body of archives information management, the archives management department should fully recognize the importance of the file management work upgrade. In the specific upgrade work, the relevant file management departments should be aware of the factors affecting the quality of the file information resource management work, and find countermeasures to solve these factors. In the development of specific archive information resources management, the archives management department should pay attention to the development of archive information resources, pay attention to the construction of archives information resources management and development equipment, change the existing thinking mode, and pay attention to improving the management of archive information resources. The work level of the team should pay attention to the promotion of archives information resources, and finally the utilization rate of archive resources information will be greatly enhanced.

\section{References}

[1] Empirical study on the maturity of archive information disclosure [D]. He Man. Zhejiang University 2018

[2] Research on Digital Archives Resource Display of Municipal Archives Websites in China [D]. Liu Guiqin. Zhengzhou University 2017

[3] Empirical study on the factors affecting the continued use of archives users [D]. Liu Yameng. Tianjin Normal University 2017

[4] Research on the evaluation index system of archives work in general undergraduate colleges in Anhui Province [D]. Wang Luzhen. Anhui University 2017

[5] User-oriented recruitment website evaluation research [D]. Li Fangling. Nanjing University 2016

[6] Research on Digital Archives Resource Quality Evaluation Index Model Based on User Experience [D]. Li Xiao. Tianjin Normal University 2016

[7] Research on performance evaluation of archive information construction [D]. Zhu Limei. South China University of Technology 2017 